\title{
Exploring Gender Responsive Pedagogy Practices and Its Management in Higher Education Institutions: The Case of Wollo University, Ethiopia
}

\author{
Bitew Atnaf Alemayehu (PhD) \\ Bahir Dar University, Ethiopia, College of Education and Behavioral Sciences \\ Department of Special Needs and Inclusive Education
}

\begin{abstract}
This study focuses on exploring Wollo University's gender responsive pedagogy (GRP) practices and the GRP management. Qualitative case study method was used for the research. Semi-structured interview and focus group discussion were used to collect the data. Three university teachers, three gender administrative office members and five female students for the were used for the purpose of in-depth interview. Besides, six female students were used for the purpose of focus group discussion. The findings indicated the university had experiences in using gender policy and gender clubs to ensure gender equity and equality in educational delivery processes. However, it had limitations in using GRP dimensions specifically: gender receptive lesson planning; gender friendly teaching and learning materials; gender friendly language use in classrooms; gender responsive classroom interaction; addressing hidden gender-based violence and negative attitude of teachers and male students towards gender equality and equity. Additionally, the university had limitations in using gender friendly management structures that utilizes: gender policy effectively; empower students and teachers on GRP; and mainstreaming gender issues in GRP. Finally, recommendations on GRP practice and its management to GRP are discussed based on the findings of the study.
\end{abstract}

Key terms: gender responsive pedagogy; practice, gender management, higher education institutions

DOI: $10.7176 / \mathrm{JEP} / 11-16-03$

Publication date:June 30th 2020

\section{Introduction}

Gender inclusion and using gender responsive teaching and learning approach has gained focus these days (Barton, 1998). This is because quality of education and gender equity and equality cannot be achieved without using inclusive and gender responsive pedagogy (FAWE, 2006). As a result, some developed countries such as countries in Nordic areas have tried to include gender responsive pedagogy (GRP) strategies to ensure gender equity and equality in educational institutions (Lamella, 2014; Kreitz-Sandberg, 2013). For the purpose of this article, the writer feels that it is important to define about gender responsiveness, and gender responsive pedagogy. FAWE (2005) defines them as follows: gender responsiveness means ensuring gender equity and equality through taking appropriate actions to gender equity and equality barriers such as bias and discrimination among male and female students to opportunities and resources in higher educational institutions. Gender responsive pedagogy means using teaching-learning strategies that give equal consideration to female and male students' needs and other background differences.

GRP has a number of benefits to achieve quality education by considering needs of male and female students. For instance, it avoids occurrence of gender stereotyping; it increases all students active participation in their learning; it empowers female students to counteract gender discrimination, it empowers teachers to use gender responsive teaching and learning strategies'; it increases female students participation in education and reduces their drop out; and it allows females to have equal opportunities to employment and participation in different areas of life (Nabbuye, 2018).Besides, GRP has advantages for both students and teachers. With respect to teachers, it helps them to include equal opportunities to students through gender sensitive educational practices and activities that meet both male and female students. In relation to students, it gives them equal chances in order to actively participate through GRP: instructional provision, classroom organization and performance assessment procedures (Abraha Asfaw, 2012).

Studies conducted worldwide show that there is gender inequality and equity problems in different areas of life including educational access and opportunities (FAWE, 2005). For example, developing countries such as countries in south of Saharan African countries use traditional teaching methods in educational institutions. As a result, in these countries, there is problem of gender equity and equality (FAWE, 2009). Additionally, global researches clearly reveal that there is prevalent problem in gender equality and equity in educational settings including higher education institutions (Allana, Asad \&Sherali, 2010). For instance, study results indicated that in educational settings teachers favor to boys in their teaching-learning processes. Furthermore, teachers used to make boys dominate classroom talk. It is also stated that and there was evidence to suggest that teachers intentionally lead the content of lessons towards male students' interest in order to keep their attention and 
control. Besides, teaching materials contents, examples, illustrations and language uses in the classroom were not gender sensitive (Simon \&Terhile, 2014). In addition, FAWE (2016) argues that limited use of GRP in subSaharan Africa was mainly due to the teachers': lack of knowledge of GRP, use of abusive and negative language that degrade females; use of teaching and learning materials that perpetuate gender stereotypes; and use of classroom interactions that hinder girls' self-esteem, healthy social interaction and related problems. Furthermore, a study conducted in Tnzania in Sokoine University of Agriculture showed that there was low level of GRP practice in the university. Besides, the instructors had limited knowledge of gender sensitive teaching practices (Cahaba, Massawe \& Kira, 2017). Likewise, studies revealed that using GRP can be negatively affected by: low proportion of female teachers; teachers who are not trained and not sensitized to gender issues; curricula which is not free from gender stereotyping and in conflict with traditional culture; and gender insensitive teaching materials. Further, GRP can be negatively affected due to school environment which is exposed to sexual harassment; along with female students financial, and other resources problems (IREX, .n.d).

The above research results suggest that inclusion of gender issue and using GRP in teaching-learning processes is important for quality education and gender equality. With regard to this issue, FAWE $(2005,2006)$ argues that teachers are required to plan their lesson that gives equal opportunities to both male and female students. Such lesson plan should include using gender sensitive: teaching and learning materials, teaching methods and strategies, educational resources, contents for teaching, instructional activities, language use, students' interaction, assessment of students learning and physical and social classroom setup. FAWE also argues that GRP practice should extend to include management of the students' sexual maturation and sexual harassment because these issues can negatively affect the students' participation in education, and healthy psychosocial developments. Additionally, FAWE $(2005,2006)$ asserts that gender responsive pedagogy could not be succeeded without gender responsive intuitional management that involves in enacting and enforcing application of gender responsive pedagogy policy, rules and regulations as well as empowering teachers, students and other staff members in GRP.

Furthermore, UNESCO (2015) asserts that educational institutions should revise their curriculum framework to explicitly state commitment to gender equity and equality. Thus, they should emphasize on including issues of attitudes and values that promote gender equality by incorporating these issues in content of the course syllabus, textbooks and learning materials.

\section{Statement of the Problem}

Achieving gender equity and equality in educational settings has importance in: developing the potential of female and male students for their learning. It also helps them improve their: psychological and social wellbeing; academic achievement, as well as reduction in dropout and repetition in their learning (Nabbuye 2018; IREX, .n.d).

Although Ethiopian higher education institutions are not isolated from using existing traditional gender serotyped and unequal teaching-learning processes, they have responsibility to serve as models for other educational institutions. In this regard, it is asserted that higher education institutions have power to produce manpower equipped with knowledge and skills of, attitudes and values towards gender equality and equity (Ogwang, n.d.).However, there is little attention on gender responsive pedagogy study and intervention in higher education institutions especially south of Saharan African counters (Orodho, 2014).

Moreover, it is asserted that GRP could not be implemented in educational institutions duet to teacher related and other variables such as school environment variables. For example, GRP implementation could be negatively affected by the teachers: unfavorable attitude towards female students' ability to learn and educational participation; lack of knowledge and skills about GRP; inclination to traditional teaching method by default; and lack of interest to empower female students. Additionally, GRP practice could be affected by school environment where teachers are not supported by school administrative staff and other relevant stakeholders (Nabbuye 2018).

From the above discussion one can infer that Ethiopian higher education institutions including the subject of this study (Wollo University) have the capacity/ power to use GRP and serve as models for other educational institutions. However, its GRP practice can be affected by teacher related and the university administrative staff related variables. Nevertheless, I felt that this should be identified by conducting research. Besides, as far as to my understanding, there is no any/little study conducted regarding GRP practices and GRP regulation systems in Ethiopian higher education institutions (including Wollo University). Thus, this paper attempts to address the following research questions: (1) What gender responsive pedagogy dimensions are practiced in the university? (2) What mechanisms do the university use to manage the gender responsive pedagogy practices?

\section{Methodology of the Study}

\section{The Research Design}

This research is descriptive by its nature. To conduct the research, I used qualitative case study research method. 
I used case study as appropriate qualitative research for this study because I want to answer the descriptive questions about the practice of GRP and its management strategy of the GRP. In this regard, Gay, Miller and Airasian (2009:443) recommended that case study is used when researchers want to "answer a descriptive question (e.g., what happened?) or an explanatory question (e.g., how or why did something happen?)"

\section{Study Setting and Data sources}

The study setting was Wollo University (WU) which is found in North West of Ethiopia, 401 kms drive from Addis Ababa, capital city of Ethiopia. WU had two campuses: Dessie Campus (main campus) and Kombolcha Institute of Technology. Both campuses have gender, disability and HIV/AIDS control and prevention offices. The data sources for the study were teachers from main campus, gender, disability and HIV/AIDS control and prevention officers from both campuses and female students from both campuses. The data were obtained from the sources through interview and focus group discussion.

\section{Samples and Sampling Methods}

Target samples for this research were three females who were in charge of gender, disability and HIV/AIDS control and prevention offices. They were purposely selected for they had better knowledge of gender and GRP. I also purposely selected three teachers (two males and one female). They were purposely selected from College of Social Sciences and Humanities and Institute of Teachers' Education and Behavioral Sciences. The rationale for selecting them was that they were supposed to have knowledge of gender and GRP because they had specialization in education and instructional strategies. The writer also selected five female students for interview and six female students for focus group discussion (FGD) from the two campuses. These interviewees and FGD participants were selected purposely based on their appointment to classroom leadership position and their being member of gender committee. Generally, the purposive sampling of the respondents was conducted based on the assumption that these selected participants could give better information about GRP and related issues.

\section{Data Collection}

Qualitative data were collected by using semi-structured interview guide and focus group discussion (FGD) guide. Interview and FGD data were collected from the participants mentioned above. Both interview and FGD participants were third year female students who were prospective graduates with their age ranging from 21-28. Additionally, interview data were collected from other key informants that included: teachers mentioned above, gender, disability, and HIV/AIDS prevention and control administration office (a director and two officers). The instructors mentioned above were the staff members who were PhD holders and had long years of experience in the university in teaching. The director and two officers were females who had experience in gender issues management and support. Regarding Gender, disability, and HIV/AIDS prevention and control administration office members, the director was $\mathrm{PhD}$ degree holder, whereas the two officers were BA degree holders.

Regarding my role during data collection, as being one of the staff members of the university, I have acquaintance with teachers, as well as the director and officers of the gender administration office. I also had some acquaintance with some students who were involved in interview and FGD members. Although I had acquaintance with the majority of the participants, I tried to stay neutral during the data collection in order not to be biased during data analysis and interpretation.

\section{Procedural Rigor}

The data were collected by gaining permission from the WU research and publication office, Gender, disability, and HIV/AIDS prevention and control office and respective departments the teachers and students who were selected from the participants.

The participants for key informants and FGD were made to participate voluntarily. They were asked to read and sign consent form to participate or not to participate. Moreover, when they were not interested to participate, they were told to quit at any time during the process of the data collection. Besides, they were also assured that codes would be used in data analysis in order not expose their identity, and related issues.

The interview data collection strategy was conducted as follows: One-to-one interview with students was conducted in empty class with each participant. Additionally, one -to-one interview with gender office personnel and teachers was done in their offices, respectively. During one-to-one interview, my role was probing and controlling the interviewee on track /on the subject under discussion. The interview was ended when I thought there was no more new information to add. The interviews process with each participant took 45 minutes on average.

Moreover, the FGD was conducted in open place outside the classrooms that was not exposed to other people's disturbance. During the focus group discussion, my role was leading discussion, controlling the discussion by probing and giving chances to each participant. I did this deliberately to encourage the 
participants' to talk freely. The FGD came to an end when I thought that there was no more new information from the participants. The focus group discussion took nearly one and half hours.

The interview and FGD data were recorded by tape recorder. The recorded data were transcribed carefully by listening repeatedly. The transcribed data were ready for analysis by using content analysis strategy that is mentioned in data analysis sub-section.

\section{Data Analysis}

The data was analyzed based on content analysis methods. The content analysis was conducted based on themes identified and developed from the collected data. Themes were developed through coding. The coding and forming themes from the data collected was done by reading and re-reading transcribed data, observing for similarities and differences to make themes and categories. This was done by production of codes and demarcation and identification of themes in addition to creation of explanations to themes.

Trustworthiness of data was ensured trough different strategies. These included reflexivity, triangulation of sources of data, peer debriefing, and member checking and extended stay in the field during the process of data collection.

The data were analyzed based on codes in order to make the study participants not to be identified by their names and identity. Hence, I used the following codes to analyze the themes: T1, T2, T3 for teachers; GoP 1, GoP2 and GoP3 for participants assigned for gender office administration; S1, S2, S3 ... for student interviewees; and D1, D2, D3... for student participated in focus group discussion.

\section{Findings and Discussion}

From the data analysis result the following themes were developed based on the first research question: GRP lesson planning, GRP teaching and learning materials, GRP classroom language use, GRP classroom interaction, GRP sexual gender - based violence and GRP management mechanisms. These thematic areas were analyzed, interpreted and discussed thoroughly.

\section{Theme One: GRP Lesson Planning}

The three teacher interviewees were asked whether or not they used to apply GRP lesson plan. They reported that they did not use gender responsive lesson plan. Although their lesson plan considered teaching and learning materials appropriateness, teaching methodologies, learning activities, assessment and feedback, their lesson plans were not aimed at gender responsiveness. The following three quoted responses illustrate the teachers GRP lesson planning practice:

"Although I know that boys and girls have specific needs in their learning, I do not consider their needs differences during lesson planning. I do not also mind girls and boys equal participation and access to resources" (T1).

"I have never heard of gender responsive teaching. I have also never taken any training on the gender responsive lesson planning. I thought this is the roles and responsibility of gender office that works in the university. I thought the gender office makes teachers give gender responsive lesson by using tutorial sessions" (T2).

"Although I feel I have to teach the students based on gender differences need, I do not use lesson plan which is planned based on gender responsive pedagogy. Infract, I try to motivate female students as much as possible to participate equally as male students" (T3).

Interview and FGD participant students were also asked whether or not their teachers use gender responsive lesson plan. Almost all the interviewees and FGD participants responded that they were not sure whether or not their teachers use GRP lesson plans. What they knew was that teachers did not use strategies in the teachinglearning processes that make equal participation of male and female students. They also responded that almost all teachers did not mind all students' active participation. They used to give chances to students who dominate class participation. They did not use strategies to check whether or not all students followed their lesson attentively and understood the lessons. The following excerpt would represent the interviewee students' responses:

I do not know whether or not they use gender responsive lesson plan to teach us. Thy do not encourage male

and female students equally. Male students who are volunteers dominate class activities and presentations.

Most of the female students keep silent during teaching-learning processes. (S3)

Moreover, FGD participant students stated that they were not sure about their teachers gender responsive lesson planning. However, they noticed that all teachers did not make all students actively participate in their learning activities. For instance, one of the discussants stated as follows:

"I think the teachers do not use gender responsive lesson plan because they always give chances to student who dominate the class learning. They also do not motivate female students equally participate in their learning. (D4) 
The above findings illustrated that the university teachers did not use GRP lesson plans for their teaching and learning activities. As stated by the teacher respondents, they had some awareness about needs differences in male and female students. However, they did not use GRP lesson plans. This happened due to their lack of taking training on GRP. This study result supports a study conducted in one of the Tanzania's Universities (Kahamba, Massawe\& Kira, 2017). The authors stated that the teachers had awareness about needs differences in male and female students but they could not use gender responsive teaching methods. This occurred due to their lack of taking training on GRP. This suggests that teachers should get training on GRP. In relation to this Warin and Adriany (2017) argue that teachers should get training on GRP before they start their teaching profession and ongoing training by in-service training means.

It is possible to infer from the current study that the teachers lack of GRP lesson plan use could lead them to failure in using teaching material that has no gender stereotyping effect; and non-abusive language use that makes female students accept about male dominance, Failure in using GRP lesson plan results in using teaching methods that does not motivate all students equally participate in their learning activities; and assessment mechanisms and feedback giving methods that do not ensure all students understood their lessons. In line with this, FAWE (2005:9-10) recommends that GRP lesson plan should consider the following issue to be gender responsive in "teaching and learning materials, teaching methodologies, learning activities, classroom set up and interaction, management of other gender constraints to learning inside the classroom and feedback and assessment."

\section{Theme Two: GRP Teaching -Learning Materials Use}

The interviewee teachers were asked whether or not the teaching and learning materials, they used to teach their students were gender responsive. All of the interviewees responded that they have awareness about the teaching -learning materials should be GRP. But they did not use to practice GRP teaching and learning materials that were free of gender stereotypes. The following quotations are drawn from the interview as samples to represent the respondents' responses:

I think I the teaching-learning materials that I use are not developed based on principle of gender responsive pedagogy. I also noticed that there are some contents and methods that are biased to male students. However, I use the teaching-learning materials as they are developed by the Ministry of Education with some modifications based on students' background knowledge and language ability" not on gender differences (T2).

I believe that teaching and learning materials should be gender responsive. In order not to discriminate girls, I try to equally distribute the teaching and learning materials to both female and male students. I think this is one of the tasks that make students equally participate in their lessons. But I do not try to make teaching and learning materials gender responsive (T3)

Moreover, interview and FGD participant students were asked whether or not the teaching and learning materials were gender responsive or not. In this regard their responses can be categorized in to two. Out of five students, three students had awareness about lack of gender responsiveness of their teaching materials. The other two interviewees did not have awareness whether or not the materials were gender responsive. The following two responses were quoted as examples from both groups of interviewees: "I noticed those examples given and the language of the materials are male dominated. There are very few examples and illustrations that use females as examples." (S1). The other group stated as follows: "I am not sure about the teaching material equal treatment of female and male students. Of course, I believe that the teaching and learning materials are biased to male domination." (S3)

Similar to the above three interviewees, the FGD participants did not have the same responses. Four of the six discussants agreed the materials are biased to males. The other two discussants reported that they did not have awareness about the teaching and learning materials gender responsiveness. For instance, one of the discussants who claimed she had awareness stayed as follows: "I think the materials examples, figures and illustrations are dominated by male characters." D(2)

The above findings showed that both teachers and majority of students reported that teachers used the nonGRP teaching and learning materials. Moreover, teachers did not try to modify the teaching and learning materials to make them gender responsive. Besides, some students had lack of awareness about whether or not teaching and learning materials were developed based on GRP principles. Additionally, this happened because of lack of knowledge about teaching and learning materials gender responsiveness.

The current study result is consistent with other studies. For example, Ethiopian Ministry of Education (MoE) (2014:31) states that in Ethiopian higher education, although there were "efforts made to mainstream gender in the instructional process, there still remains work to avoid gender stereotyping in the curricula and the pedagogy." The current study result also supports with researches Conducted in Swaziland (Lumadi \&Shongwe, 2010) and Tanzania (Kahamba, Massawe \& Kira, 2017). These studies findings revealed that teaching -learning materials and methodology used for the purpose of teachers training were not gender sensitive. Teachers did 
not have knowledge and skills in how to make teaching and learning materials gender responsive.

As stated above, the current study results related with using non gender responsive teaching and learning materials in the long-run may result in making students believe that gender inequality in education and other activities is normal. With regard to this, FAWE (2005:12) asserts that teaching and learning materials that are not gender responsive send the message that "women and girls are weak, passive and submissive. They are mostly depicted in domestic, care giving and supportive roles. On the other hand, men are "portrayed as powerful, assertive and intelligent, as well as leaders in society."

The above discussion suggests that there is a need to train teachers to modify teaching and learning materials gender responsive. In relation to this FAWE (2006), argues that teachers need to adapt the teaching and learning materials to make them gender responsive. Additionally, they have to make illustrations, charts, pictures, diagrams and other teaching aids gender responsive. Generally, they need to get training on how to make teaching and learning materials gender responsive.

\section{Theme Three: GRP Language Use in the Classroom}

The interviewee teachers and students stated that language use in the institution was biased to males. Teachers, students and other university community have biased language use that had gender stereotype. For instance, one of the female student interviewees reported that language use as barrier to gender equality. She said that one of the teachers while he was conducting examination and found a female student cheating used stereotyping language that degrades female students learning. She stated the situation as follows: "Stupid! You joined the university without your effort and you trouble us. It is better for you to find a job that fits your ability than wasting your time here."

One of the interviewee teachers (T3) also stated that language use in the university was a reflection of the society where the students and teachers come to the university. The teacher explained the origins of the language use problem that perpetuates gender inequality in educational institutions. The languages are embedded in sayings, proverbs, songs and jocks. For instance, the teacher interviewees gave the following proverbs that make society to develop negative attitude towards gender responsive education:

"Whatever is known by a woman, a man concludes."

"One cannot find wise woman and donkey with horns."

"Woman and horse become lower and lower like a pond that decreases as time goes on."

"A man's decision is accomplished within a day, but a woman's decision takes a year to be accomplished."

The other teacher interviewee responded as follows: "I use teaching materials prepared developed by MoE. I am sure that these materials are gender responsive. I noticed that the language that is found in the teaching and learning materials is male dominated or biased to males." (T2).

The above finding reflects that language use in teaching and learning process were not gender responsive. This results in promoting gender inequality in the university in general and in classrooms in particular. With regard to this (UNESCO, 2015) argues that gender biased language use that degrades females and reflects male dominance results in reinforcing gender differences and inequalities. Thus, teachers and students need to use inclusive language in the classroom in order to promote gender equity and equality. This is because gender insensitive language use demotivates female students' active participation in their learning and makes them accept male dominance. Besides, gender biased language use also hinders female students to communicate openly and participate actively.

This suggests that both teachers and students should use gender responsive languages which treat male and female students as equal partners and creating equal opportunities for their learning (FAWE, 2006). Moreover, INEE (2010) states that language uses in teaching-learning processes, by teachers' and students should be gender sensitive, non-violent and non-abusive. Additionally, teachers and students ought to avoid using jokes; proverbs and terms that stereotype or belittle either sex.

\section{Theme Four: GRP Classroom Interaction}

All of the teacher and student interviewees and FGD participants stated that there were limitations in gender responsive classroom interaction. That means students did not have opportunity to exercise GRP Classroom Interaction. For example, the following quotation taken from teacher and student interviewees and FGD participants illustrate the situation of gender responsive classroom interactions:

I think students sitting in classrooms do not create gender responsive pedagogy. For example, female students sit together without mixing with male students. Male students also prefer to sit with male students. This creates less interaction between male and female students. Additionally, most teachers' especially young teachers' way of dressing is not different from their students that do not make them models to their students. (T1)

Many teachers are biased to male students; they simply make students participate who are voluntary to 
participate in activities, discussions and presentations. In most cases teachers call on male students more frequently than females, they ask males more questions than females, give male students more eye contact following questions. Many teachers also use languages that demotivate female students. For example, they consider females as dependents on male students in assignments, tests and exams. (S4)

Many teachers do not make female students participate equally as male students. In fact, most of the female students prefer to be silent during class activities, discussions and presentations. They prefer to give this chance for male students. Moreover, majority of teachers do not give equal chance for female to equally participate in class activities, group discussions and presentation (S1).

Some students' way of dressing is unusual. There are both male and female students who dress in a way that provokes sexual harassment. There are also students who are addicted to substances who show deviant behaviors such as bulling females and provoking sexual activities. (S5)

There are teachers who degrade female students. They consider female students as weak and joined the university by affirmative action. As a result, they do not give equal chances to female students to class activity, assignment and group leadership. (D2)

The above quotations depict that male and female students and teachers and students interaction were affected by different variable such as the teachers favoring to male students; students interaction based on sitting and unusual dressing and showing deviant behavior. This result supports a study conducted by Abraha (2012: 7) which states that in higher education institutions "classroom interactions tend to focus on male participation. The fear of sexual favoritism limits girls' freedom of participation and interaction with others."

Moreover, the current study finding illustrated that student and teachers characteristics mentioned above create negative result on healthy classroom interaction. It creates female students victims of male domination, sexual harassment and inactive in their learning. Such interactions are obstacle to using GRP based classroom interaction. With regard to the issue under discussion, FAWE (2006:23) says that when there are limitations in gender responsive interaction in educational settings, "sexual harassment, male domination and female passivity come into play". FAWE also asserts that students sitting based on same sex reinforce gender differences and stereotypes. It makes female students more passive and dominated by male students. Thus, it necessitates using efficient GRP based classroom interaction strategies.

\section{Theme Five: Gender Based Violence (GBV)}

Another theme developed from the collected data was GBV. The student interviewees and FGD participants described that there was GBV in the university by teachers', students and other university community members. However, the gender management personnel reported that there is little or no GBV in the university. They stated that GBV is prevented and controlled by gender equity and equality policy with strong code of conduct and involvement of gender clubs. Nevertheless, the interview and FGD participants' students reported that although the university uses equity and equality policy and gender club's involvement, there was hidden sexual harassment that students did not used to report to the gender office and other administrative body. The hidden sexual harassment according to the participants' refers to sexual harassment which is not seen by gender clubs and other concerned bodies and reported to them by the victims. It is only dealt by perpetrator and victims in a secret way that is not known to a third party. The following quotations taken from gender office personnel and student interviewees' represent their responses to the issue under discussion:

The university has code of conduct and gender clubs to prevent and control sexual harassment and other gender based- violence. The university has zero tolerance to gender based- violence. For instance, it has experience in punishing sexual harassment perpetrators. It has experience of prevention and controlling of gender discrimination. (GoP1)

The university has code of conduct and gender clubs regarding gender equality. The university has experience of punishing sexual harassment perpetrators based on code of conduct. However, there are hidden sexual harassments by teachers and students that the university could not prevent and control it because of problem of the victims' failure to report the cases to gender office. (S3)

Additionally, the FGD participants supported the student interviewees' position about use of gender policy implementation and hidden sexual harassment practice in the university.

It is possible to infer from the above finding that the gender office representatives had lack of awareness about hidden GBV and how to prevent and control it. It is also possible to understand that female students who were victims of hidden sexual harassment might have experienced psychological problems on their learning if the perpetrators are especially their teachers or class mates which may lead them to psychosocial and academic achievement crises. In connection with this, FAWE (2005: 24) argues that sexual harassment victims by their teachers or others who have close contact during their learning makes them feel traumatized and could face attention problem in their learning. Besides "the presence of the perpetrator will elicit rage, anxiety and hatred that may hinder learning." Furthermore, UNESCO (2008) asserts that sexual harassment to female students' results in low self-worth, reduced participation in education activities, and the like. 
The female students' gender-based violence in the current study is consistent with MoE (2004) study report. The MoE study revealed that in Ethiopian higher education institutions female students suffered from security and protection problems due to physical and sexual harassment incidences around classes, cafeteria, and library and study spaces. This is also partially consistent with Abraha (2012) study result which stated that in Ethiopian higher education institutions there was bias and discrimination against female students which in turn resulted in female students' high dropout and low academic achievements.

The above discussion suggests that there is a need to develop strategies to identify hidden sexual harassment take intervention by using effective implementation, monitoring and evaluation of GRP. This also suggests that the university should conduct study to identify psychosocial wellbeing of the hidden sexual harassment victims and conduct appropriate intervention strategies.

\section{Theme Five: GRP Regulation}

The gender office management personnel as well as interviewee and FGD participant female students were asked what mechanisms the university uses to regulate GRP implementation in the university. The following themes were developed from the data collected: empowerment and using GRP policy.

\section{GRP Policy}

The university gender office personnel and interviewees and FGD participant students reported that the university had GRP policy with code of conduct aimed at preventing and controlling gender equality problems. For example, the gender office personnel reported that students are made aware of GRP code of conduct including gender-based violence and how to report to gender office. On the other hand, students' interviews and FGD participants stated that the university had code of conduct; however, the code of conduct could not prevent GBV especially hidden sexual harassment. The following three quotes illustrate the respondent responses:

There is zero tolerance to gender violence and other discrimination against female students. We have gender policy that focuses on prevention and controlling. We have also code of conduct that helps us to take measures on the people who are in charge of gender violence. We have also experience in controlling the gender discrimination in teaching and learning process. (GO2)

The university has code of conduct for gender discrimination and gender office that tries to work had to prevent and control gender inequity and inequality. However, there is no awareness creation regarding gender equity and equality code of conduct and how to use it for gender cases such as gender violence and other forms of gender discrimination to teachers, students and other staff members. (S4)

The university has encouraging system in gender problems management. For example, it has code of conduct with zero tolerance to gender-based violence. However, the University does not have strategy to make gender issues awareness to students, teachers and other staff members. (D3).

The above statements described by the respondents showed that the university had mechanisms to control gender -based violence. It uses code of conduct to take measures based on reported gender discriminations. However, the policy was not made known to university staff and all students in order to be internalized to all university community to be effectively implemented. Unless it is known to the concerned body, the policy could not be implemented to gain expected result. Thus, the management strategy has to be implemented with code of conduct that help to implement effective GRP. With reference to this, FAWE (2006) recommends that the gender management has roles and responsibilities to frame, apply and control the GRP by using "rules and regulations" that help to create conducive environment to implement GRP.

\section{Empowerment in GRP}

Another theme developed from the data was empowering students and teachers through establishing gender clubs and training on GRP. Gender office personnel explained that they used to give awareness training when a new students batch join the university. They also explained that the university had gender clubs that were aimed at creating awareness to the university community members about the gender issues. They also reported that even though there were efforts of gender clubs' involvement in GRP, they were not empowered to create awareness about GRP to the university community.

The interviewees also reported that they used to give chances to at least to one female student in each classroom to exercise leadership skills in classrooms. Moreover, the university had experience of giving opportunity to female teachers and administrative staff members to leadership position in order to make them models to female students. However, the female students who were given opportunity to lead classrooms were not made to take training in how to exercise leadership in their classrooms.

The obtained data from the gender management office revealed that teachers and students were not empowered on GRP through training. The respondents' reported that they did not give training to empower both students and teachers on GRP. The respondents added that the issues of GRP were not mainstreamed in all GRP activities to empower teachers and students in GRP. The following excerpt was taken from the respondent to 
illustrate what was reported by the respondents:

We empower female students and female staff members by taking them to leadership positions. The university does this task to ensure gender equality in the university. What is lacking in our system is training of teachers and students in gender responsive pedagogy and mainstreaming of gender responsive pedagogy in the university activities (GOP1)

Moreover, all of the student interviewees reported that they had equal chances in empowering female students in exercising leadership skills. However, they said that they did not get opportunity on how to exercise and develop leadership skills. They also reported that teachers and male students had negative attitude towards female students' appointment to leadership position. They also added that there should be awareness training for teachers and students about GRP.

The following quoted examples illustrate the interviewees' responses:

The university has given chances for female students to be equally represented in the classrooms' issues. I think this is good chance to exercise gender equality in teaching and learning processes. Infarct, there are teachers and male students' negative attitude towards equal opportunities to representation of female students in classroom leadership positions (S4).

The teacher respondents also reported that they did not get training on GRP. As a result, they did not believe in gender equality practices. Because they consider gender issues as political issues that government uses for political purpose that cannot be implemented in real world such as in universities. For instance, one of the respondent teachers stated as follows:

I have some kind of concept about gender equality in teaching and learning processes as well as empowering females for leadership position. But I have not had training on gender responsive teaching-learning process. Besides, I feel that this is political issue that government uses to actively involve woman in political agenda to get women's favor in political issues (T3).

From the respondents report one can infer that the university had encouraging practice in giving equal chances to female students and staff members to be empowered in leadership positions in order to ensure gender equity and equality. However, the university lacks empowering teachers, students and administrative staff through giving training on GRP. There were also teachers and male students' negative attitude towards female students' empowerment by taking equal chances in leadership positions. This finding shows that there is a need of attention of the university concerned bodies to empower the students and teachers and other staff members in GRP. There is also a need to give priority to mainstreaming the issues of GRP in all activities of the university. If the empowerment and mainstreaming are not conducted, there is a high chance to the continuation of gender inequity and inequality in the university's implementation of the GRP. In relation to this issue, Tatar and Emmanuel, 2001 argue that if teachers do not get training on gender equity and equality in the process of teaching-learning, they stereotype female students learning, decision -making, assertiveness and related issues. Moreover, FAWE (2005) contends that both male and female students should be empowered in knowledge and skills about gender responsive pedagogy that in turn promotes gender equity and equality. Besides, researchers recommend that gender responsive pedagogy should be given to teachers at both pre-service and in-service training programs (Abraha, Asrat \& Amera, 2019).

This study has some limitations. they are first one is that the writer focused on only one university that could make the study difficult to generalize to other universities. Another limitation is focusing on only female students and teachers from two colleges as participants. Had I included other teacher participants from different colleges and male students, the study could have been with better findings about the issue under discussion. Thus, further studies can be done to address the limitations mentioned above.

\section{Conclusions}

WU had experiences in using gender policy and gender clubs to ensure gender equity and equality in educational delivery processes of the university. However, the university had limitations in using GRP specifically: gender receptive lesson planning; gender friendly teaching and learning materials; gender friendly language use in classrooms; gender responsive classroom communication; addressing hidden gender-based violence and negative attitude of teachers and male students towards gender equality and equity. Additionally, the university had limitations in using gender friendly management structures that utilizes: gender policy effectively; empower students and teachers on GRP; and mainstreaming gender issues in GRP. There was also misconception about considering gender issue as political issue that the government uses it to get support from females.

The current study result suggests that WU had limitations in using GRP implementation that is key to produce man power that believes in and practices gender equity and equality. In relation to this notion, Epstein \& Johnson (1994:34) argue that failure to use gender responsive pedagogy in schools ensures the continuation of "gender biased practices appear normal and cultural, and thus acceptable" in the society where gender inequality is treated as normal. Failure to use gender responsive pedagogy also suggests limitations in providing quality education in a way that meets unique needs of male and female students (UNESCO, 2004; FAWE,2006; INEE, 


\section{Recommendations}

The findings of the study revealed that WU had limitations in GRP practices and GRP management regulation strategy. Thus, the university should: strengthen gender policy code of conduct and gender clubs in a way they can utilize GRP concepts and practices in the university; empower teachers on GRP concepts and skills in order to use appropriate GRP(GRP lesson plan, GRP teaching and learning material, GRP classroom interaction, and GRP language use); empower both male and female students and gender clubs on GRP to ensure gender equity and equality in teaching -learning processes; devise strategies to prevent and control hidden gender based violence as well as teachers and male students negative attitude towards gender equity and equality; and mainstream issues of GRP in all areas of GRP activities. There is also a need to conduct further research by concerned bodies on the issue under discussion in order to get reliable evidence to conduct appropriate intervention on GRP of the university.

\section{References}

Abraha A.(2012). Gender inequalities in tertiary education in Ethiopia: mediating the transition to university through the development of adaptive competencies. Global Scholars Program Working Paper Series.

Abraha, M., Asrat D., and Amera S.(2019). Gender responsive pedagogy: practices, challenges

and opportunities: a case of secondary schools of North Wollo Zone, Ethiopia. Journal of Education, Society and Behavioural Science 30 (3), 1-17.

Allana,A. , Asad , N. and Sherali, Y.(2010). Gender in academic settings: role of teachers.

International Journal of Innovation, Management and Technology, 1 (4).

Barton. A. C. (1998). Feminist science education. New York: Teachers College Press.

Epstein, D. and Johnson, R. (1994). On the straight and narrow: the heterosexual presumption,homo-phobias and schools. In D. Epstein (Ed) Challenging Lesbian and Gay inequalities in Eduction. Buckingham: Open University Press.

FAWE (2005). Gender responsive pedagogy: a teacher's handbook. Nairobi: Kenya, Forum for African Women Educationalists (FAWE)

.....(2006). Gender responsive pedagogy. Retrieved from http://www.adeanet.org/adea/biennial2006/doc/document/B5 2 fawe_en.pdf.

......(2009). Gender-responsive pedagogy. Retrieved from http://www.fawe.org/activities/ interventions/GRP/index.php?lang=2\&lang $=1$.

......(2016). Case study: documentation of gender responsive pedagogy as a best practice by the Forum for African Women Educationalists (FAWE). Retrieved from file://C:/Users/masitewal.t_maryam/Downloads/FAWECaseStudy_Final\%20(1).pdf

Gay, Miller and Airasian, 2009). Gay, L.R., Mills, G.E. and Airasian, P. (2009) Educational

Research Competencies for Analysis and Applications. Pearson, Columbus.

INEE, 2010). Gender equality in and through education: INEE pocket guide to gender. Geneva:Switzerland. Retrieved from http://www.ungei.org/INEE_Pocket_Guide_to_Gender_EN.pdf

IREX, .n.d). ). Developing Gender-Responsive Learning Environments toolkit. U.S Department of State's Bureau of Educational and Cultural Affairs. Retrieved from https:// www.irex.org/sites/default/files/node/resource/creating-supportive-learning-environments-girls-boys_2.pdf

Kahamba, J .S. Massawe, F. A. \& Kira, E.S.( 2017). Awareness and practice of gender responsive pedagogy in higher learning institutions: the case of Sokoine University of Agriculture, Tanzania. Journal of Education, Humanities and Sciences, 6 (2), 1-16.

Lahelma, E. (2014). Troubling discourses on gender and education. Educational Research, 56(2): 171-183.

Lumadi, M.W. and Shongwem, D.S, (2010). The need for training gender-sensitive teachers: addressing education challenges for gender sensitive national development. Contemporary Issues In Education Research 3(3), 41-50.

Kreitz-Sandberg, S. 2013. Gender Inclusion and Horizontal Gender Segregation: Stakeholders' Strategies and Dilemmas in Swedish Teachers' Education. Gender and Education, 25(4): 444-465.

MoE. (2004). Five-year strategic framework for enhancing women's participation in tertiary education in Ethiopia institutions. Women 's Affairs Department, Ministry of Education: Addis Ababa.

Nabbuye, H.(2018). Gender-sensitive pedagogy: the bridge to girls' quality education in Uganda. Echidna Global Scholars Program. Retrieved fromhttps://www.brookings.edu/ wpcontent/uploads/ 2018/11/HawahNabbuye-FOR-WEBSITE.pdf

Orodho, J. A. (2014). Policies on Free Primary and Secondary Education in East Africa: Are Kenya and Tanzania on Course to Attain Education for All (EFA) Goals by 2015 IOSR Journal of Humanities and Social Science (IOSR-JHSS), 19(1), 11-20. 
Ogwang, C. (n.d.). Re-Engineering gender equality in higher education. Progressive Institute of Business Studies, Uganda.

Simon, A.O and Terhile, B.F.(2014). Gender equality in schools: implications for the curriculum, teaching and classroom interaction. Journal of Education and Practice, 5 (32).

Tatar, M., \& Emmanuel, G. (2001). Teachers' perceptions of their students' gender roles. The Journal of Educational Research, 94(4), 215-224.

UNESCO (2004). Education for all: The quality imperative. Paris: UNESCO. (2008). Overcoming Inequality: Why Governance Matters. Education for All Global Monitoring Report. Oxford, UK: Oxford University Press. http://unesdoc.unesco.org/images/0017/001776/177683E.pdf.onitoring (2015). 2015. A guide for gender equality in teacher education policy and practices. Retrieved from http://unesdoc.unesco.org/images/0023/002316/231646e.pdf

Warin, J. \& V. Adriany. 2017. Gender flexible pedagogy in early childhood Education. Journal of Gender Studies, 26(4), 375-386. 